\begin{tabular}{|l|l|}
\hline Postprint Version & 1.0 \\
\hline Journal website & $\underline{\text { http://www.sciencedirect.com/science/journal/02666138 }}$ \\
\hline $\begin{array}{l}\text { Pubmed link } \\
\text { http://www.ncbi.nlm.nih.gov/entrez/query.fcgi?db=pubmed\&cmd=Retrieve\&dop }\end{array}$ \\
\hline DOI & $\underline{\mathrm{t}=\text { AbstractPlus\&list_uids=17174455\&query_hl=10\&itool=pubmed_docsum }}$ \\
\hline
\end{tabular}

This is a NIVEL certified Post Print, more info at http://www.nivel.eu

\title{
Workload of primary-care midwives
}

\section{T.A. WIEGERS}

Netherlands institute for health services research (NIVEL), P.O. Box 1568, 3500 BN Utrecht, The Netherlands E-mail address: t.wiegers@nivel.nl.

\begin{abstract}
Objective: to assess the actual workload of primary-care midwives in the Netherlands.

Background: In 2000, a strike and large demonstration before parliament convinced everyone of the shortage of midwives and their excessive workload. The government reacted by increasing the capacity of the midwifery schools and lowering the 'standard caseload' for a full-time working midwife. To assess whether this would lead to sufficient improvement of the situation, more insight was needed of the actual workload of midwives in primary care.
\end{abstract}

Method: a 4-year prospective survey of the work of primary-care midwives, during 3 weeks each year, including all midwives working in a representative sample of midwifery practices. On average, 224 midwives participated each year. During 3 weeks in the summer and autumn, midwives kept a diary of their work, with an accurate timetable, covering 24 hours a day. They also filled out questionnaires about practice organisation, work schedules and experiences of workload.

Findings: primary-care midwives worked an average of 29 hours a week, and about 74\% of their time (22 hours a week) was spent on client-related activities. On average, a midwife was on call during 53 hours a week, and 17 of the 29 hours of work took place during on-call-hours. This meant that an average midwife was involved in her work 65 hours a week. The time spent on direct client care increased by nearly $20 \%$. In particular, the average time spent with a woman during labour and birth increased by almost onethird.

Conclusion: primary-care midwives spend an average of 29 hours per week working, and this has remained constant between 2001 and 2004. In client-related care, there has been a shift towards fewer clients per midwife but more time per client.

\section{INTRODUCTION}

In the Netherlands, as in many other European countries, midwives play a central role in providing maternity care. In other countries, practically all births take place in hospital; however, in the Netherlands, home is still the preferred place to give birth for many women with a low-risk pregnancy. Midwives are important in preserving the system that enables low-risk women to give birth at home. In this paper, I present the results of a study looking specifically at workload of primary care midwives in the Netherlands. The reason for conducting this study was the previous shortage of midwives, which threatened the unique Dutch system of maternity care and resulted in excessive workloads and reduced quality of midwifery care. First an explanation will be given of the current position of midwives and the organisation of midwifery care in the Dutch health-care system. 


\section{DUTCH HEALTH-CARE SYSTEM}

Primary care in the Netherlands is readily accessible, outside the hospital. It is provided by medical practitioners, such as general practitioners (GP) and midwives, or others such as community nurses and physiotherapists. Secondary care in the Netherlands is hospital-based care, and is only accessible after referral from a primary-care provider: a GP or, in the case of maternity care, a midwife. Tertiary care is highly specialised hospital care in university hospitals. All medical specialists, such as gynaecologists are secondary or tertiary-care physicians.

\section{POSITION OF MIDWIVES IN DUTCH HEALTH CARE}

In the Netherlands, midwives are medical practitioners with a restricted competence (i.e. their competence encompasses only medical aspects related to pregnancy, childbirth and the puerperium of healthy women). However, within these boundaries, they are autonomous medical practitioners. Midwifery involves 4-years of vocational training, with a degree at bachelor level. A registered midwife is fully qualified to provide prenatal and postnatal care and to assist with normal childbirth, whether at home or in hospital, but is not permitted to use any instruments such as forceps, or to give an epidural. For women at low risk, gynaecologists do not need to be consulted. However, when complications arise, the risk of complications increases or the woman needs medical pain relief, the midwife will have to transfer responsibility to secondary care by referring the woman to a gynaecologist. An extensive list of indications, in 1999 agreed upon by all practitioners involved in obstetric care (gynaecologists/ obstetricians, midwives and GP), is used to select which women can stay in primary care and which need referral to secondary care (CVZ, 2003). This risk selection is the task of the primary care midwife and, occasionally, the general practitioner.

Most midwives (80\%) in the Netherlands work in primary care (i.e. outside a hospital, practising all aspects of midwifery care). As with GP for general health care, midwives are freely accessible to anyone who needs midwifery care. If clients are at low risk, they can choose to give birth at home or in hospital, accompanied by their own midwife. In cases of increased risk, the midwife will refer the woman to secondary care and the birth will take place in hospital, supervised by a gynaecologist. Not included in this study are midwives working in hospitals who care for women who have been referred to secondary care. Because care for highrisk women is not included in the formal competence of a midwife, these midwives work under supervision of a gynaecologist.

\section{ORGANISATION OF PRIMARY-CARE MIDWIFERY}

In January 2004, 1450 midwives were practising in primary care (excluding locums) (i.e on average 5.3 midwives per 10,000 women of childbearing age [15-39 years]). In 2000, the figure was 4.3 per 10,000 women (1214 practising midwives). Primary care midwives work in private practice, either as self-employed practitioners (82\%) or as employees in a midwifery practice $(13 \%)$ or a health centre (5\%). In 2004, 73 midwives (i.e. 5\% of all primary care midwives) were working in single-handed practice, $13 \%$ worked together with one colleague, and $82 \%$ were working in group practices (three or more). The average practice size in 2004 was 3.2 midwives (Kenens and Hingstman, 2004). Most pregnant women (80-85\%) receive midwifery care from the start, but, in the course of pregnancy and labour, about half of them will be referred to secondary care, resulting in $60 \%$ of all births occurring in secondary care under supervision of a gynaecologist and $40 \%$ of all births occurring in primary care, supervised by a midwife (or occasionally a general practitioner). Of those $40 \%$ of all births, about three-quarters (30.3\% of all births in 2000, 29.4\% in 2002) are homebirths (Fig. 1) (Anthony et al., 2005).

\section{[ FIGURE 1 ]}

Payment for midwifery care is by fee-for-service. The midwife can either charge the unit price for complete client care or she can charge for partial (prenatal, natal and/or postnatal) care, depending on the referral status of the woman and the time of referral (before, during or after the birth). There is a separate charge for ultrasound scans. These fees include surcharges for indirect client care and for non-client-related activities. No separate fee is charged for being on call, because 'being on call' is not regarded as work as such but as 'being ready to go to work' or 'being available for work if needed'. 


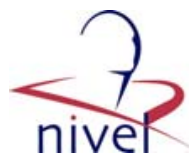

On the basis of a 'normative' annual income, a 'standard caseload' (number of clients) is calculated. In 2000, the 'standard caseload' for a fulltime working midwife was reduced from the equivalent of 150 to the equivalent of 120 births a year. This includes all prenatal, natal and postnatal care, and all nonclient related activities necessary to keep the practice functioning. On average, $26 \%$ of a midwife's working time is spent on non-client-related activities (i.e. financial administration, practice organisation and study), and $74 \%$ is spent on direct (face-to-face) and indirect client care.

Because most primary-care midwives are selfemployed, their working hours are not fixed, but depend on the actual caseload in the practice and the average time spent per client.

\section{BACKGROUND AND RESEARCH QUESTIONS}

In the Netherlands, the number of births decreased in the early 1990s, and a further decrease was expected (CBS, 1997). However, between 1997 and 2000, the number of births increased unexpectedly (CBS, 2001). This stretched the limits of the available midwifery care. A shortage of midwives and widespread complaints about excessive workloads were the immediate results. Midwives felt they could not spend enough time with their clients, because the next client would already be waiting. Neither could they take on an extra colleague to help reduce the workload because of insufficient midwives and funding. A strike and a large demonstration before parliament convinced everyone of the shortage of midwives and their excessive workload. The government reacted by increasing the capacity of midwifery schools and lowering the standard caseload for a full-time working midwife (Ministry of Health, Welfare and Sport, 2000). To assess whether this would lead to sufficient improvement of the situation and ensure that the quality of midwifery care would be maintained, more insight was needed into the actual workload of midwives in primary care and the time spent on client care. Earlier research about workload of primary-care midwives dated from 1993 (Jabaaij et al., 1994; Jabaaij and Meijer, 1996) and clearly needed updating. This led to the following research questions: (1) what is the actual workload of a primary-care midwife in the Netherlands (i.e. what is the average number of hours a primary-care midwife is working per week)?; and (2) what is the actual time a primary-care midwife spends on different aspects of client care?

\section{METHOD}

To answer these questions, a representative sample of midwifery practices were asked to participate in the study. Selection was based on two stratification criteria: level of urbanisation and practice type (single-handed, duo- or group-practice), because these variables are expected to be correlated to workload of midwives. In 4 consecutive years, an average of 71 midwifery practices (about one-sixth of all midwifery practices), with on average 236 midwives, participated in the study each year.

Practices that declined further co-operation were replaced with practices that had comparable levels of urbanisation and number of midwives. Over the 4 years, a total of 115 midwifery practices participated in the study: four times $(n=36)$, three times $(n=16)$, twice $(n=32)$ and once $(n=31)$. Each year, during 3 weeks in late summer and early autumn, the midwives (on average 224 [95\%] of all midwives working in these practices during the study period) kept a diary of all their work-related activities with an accurate timetable, covering 24 hours a day. For instance, during consulting hours, they would note the exact time of their arrival at the practice, their travelling time, the duration of the consultations, the number of clients seen during that time, the kind of contact (booking, regular, postpartum). When called to a birth, they were asked to note the time of the call, the amount of time spent with the woman, the place of birth, and so on. They were also asked to note the exact time spent on administrative tasks, whether those tasks were client-related or non-client-related, the time spent on consultation with colleagues, other health-care professionals or others, and the start and duration of their on-call hours. In other words, a complete description of their work, what they do, where they go, how long it takes, how the work is spread out over 24 hours and over weekdays and weekends. In addition to that, they filled out questionnaires about practice organisation, work schedules, time spent on certain activities in the previous 6 months, and experiences with workload. The registration period was carefully chosen for each practice to represent an average level of workload, and the midwives were asked to rate afterwards how representative the period had been. In earlier research on workload of midwives (Jabaaij et al., 1994) and community nurses (Vorst-Thijssen et al., 1990), which compared self-reported data and data collected by observers, the method of self-reporting was shown 
to be valid. In the Netherlands, no ethical approval is required for research in which no interventions take place. It is sufficient to explain to potential participants that they are free to participate and that their privacy is guaranteed.

\section{Results}

Between 2001 and 2004, each year more than 200 midwives returned the time-registration forms and questionnaires, with an average of 224 midwives per year. Over the years, 38\% of midwives rated the registration period as representative of their average workload, 50\% rated the period as (slightly) less busy than average and $4 \%$ rated it as busier than average. The results show that primary-care midwives worked on average 29 hours per week, and about 74\% of their time (22 hours per week) was spent on client-related activities (Table 1). Some fluctuations have taken place over the years, but the differences are small and not relevant. Throughout the years, an average of $20 \%$ of the actual work (5.8 hours per week) took place during evenings or nights (i.e. between $18.00 \mathrm{hrs}$ and $08.00 \mathrm{hrs}$ (not in table).

\section{[ TABLE 1 ]}

However, the differences in actual working hours between individual midwives were found to be large. The average number of working hours per week ranged from less than 10 to more than 50 hours a week (Fig. 2). This means that some midwives worked on average less than 10 hours a week, whereas others worked on average more than 50 hours a week. Self-employed midwives usually worked more hours a week than midwives with a contract of employment (on average 30 vs. 22 hours in 2004).

\section{[ FIGURE 2 ]}

The average of 29 hours per week is the number of hours the midwife was actually working, which included face-to-face client care, indirect client care (client administration, consultation with colleagues and other health-care providers) and non-client-related activities (practice administration, study). It did not include the on-call hours, in which no work was done. On average, a midwife was on-call 53 hours a week, but actually worked 17 of those 53 hours. The other 12 hours of work was when she was not on call (Fig. 3). This means that an average midwife was involved in her work 65 hours a week, of which 29 hours were work.

\section{[ FIGURE 3 ]}

The average number of working hours per week did not change between 2001 and 2004, but the number of on-call hours decreased, from an average of 56 hours per week in 2001 to an average of 51 hours per week in 2004. This reduction of on call hours per midwife is not directly related to the workload but to the increase in the number of midwives per practice.

On the basis of the time-registrations of individual midwives during 3 weeks a year, the total time a midwife spends on standard client care for a woman at low risk, from the booking visit until the final consultation 6 weeks postpartum, has been calculated (Table 2). Standard care consists of a booking visit, an average of 11 prenatal consultations, one consultation (including ultrasound), care during labour and birth. Six postnatal visits in 2001 and 2002, five postnatal visits in 2003 and 2004, and a final consultation 6 weeks postpartum.

\section{[ TABLE 2 ]}

In 2001, all aspects of standard care totalled 601 mins (i.e. 10 hours of direct client care per lowrisk client). In 2004, that was 712 mins, or almost 12 hours per client, an increase of nearly 20\%. In particular, the average time spent with a woman during labour and birth increased, by almost onethird, from slightly more than 3 hours to 4 hours and almost 40 mins. The total time spent on postnatal visits in 2004 did not differ from 2001, although there were fewer visits. 


\section{Comparison with other health-care workers}

The average workload of a primary-care midwife, measured in hours of actual work, is about 29 hours per week. This is similar to the workload of other female health-care workers, such as occupational therapists (27 hours per week), exercise therapists (according to the Cesar or Mensendieck method) (29 hours per week), or female primary-care physiotherapists (30 hours a week). For more information about health care workforce in the Netherlands, see Registration data, concerning the number of practicing professionals in primary health care, 2006 at www.nivel.nl/beroepenindezorg/.

\section{The difficulty of international comparisons}

To compare the workload of Dutch midwives with that of midwives in other countries is practically impossible because of the lack of comparable data. What are the average working hours of midwives in the UK, Sweden or Ireland? And exactly how much and what kind of work is done in those hours? How much time is spent with each client? The only comparison possible is about workforce in total: the number of medical practitioners in relation to the population. Although informative, workforce alone does not explain workload.

For instance, in the Netherlands, the number of practising midwives (in primary and in secondary care) in 2003 was 12.1 per 100,000 inhabitants; in the UK, 62.1; in Sweden, 70.6; and in Ireland, 421.9 (Eurostat, 2005). The number of practising physicians in these countries is similar: 3.1 per 1000 population in the Netherlands, 2.2 in the UK, 3.3 in Sweden and 2.6 in Ireland (OECD). The number of practising general practitioners (GPs) per 100.000 inhabitants in the Netherlands is somewhat lower (50.5) than in the UK (57.9), Sweden (55.9), and Ireland (59.5) (WHO, Health for all Database. GP per 100,000 in 2002). These differences are related to the different healthcare systems in these countries and to the position and job description of midwives within these systems. (For more background information about health-care systems and the organisation of midwifery care in different countries or especially the Netherlands (see DeVries et al., 2001 and De Vries, 2004).

Primary-care midwives in the Netherlands are involved in more than $50 \%$, and are the responsible caregiver in almost $40 \%$, of all births (Fig. 1). The involvement of secondary-care midwives (hospitalbased midwives) is not visible in the available data but is substantial. In England, with about five times as many midwives per 100,000 inhabitants, midwives are involved in $66 \%$ of all births (NHS Maternity Statistics, England: 2003-2004). However, workload data cannot be compared because of the difference in organisation of midwifery care.

Since the government report ‘Changing Childbirth' (1993), various changes were introduced in the organisation of midwifery care in the UK, such as team-midwifery, midwife-led-units and case-load midwifery. According to the descriptions of Stevens and McCourt (2002a, b and c), case-load midwifery resembles primary-care midwifery in the Netherlands (i.e. includes all aspects of midwifery, establishing working relationships with colleagues and other health-care providers, assuming responsibility for quality and appropriateness of care and for referrals, and establishing and maintaining professional and personal boundaries). However, unlike these caseload midwives, primary-care midwives in the Netherlands do not carry a personal case load and are not responsible for high-risk clients. Stevens and McCourt, 2002a, b and c give no information about the actual workload of these midwives, their working hours or time spent on different tasks. Therefore, no comparison is possible with the workload of Dutch midwives, as described in this paper.

\section{DISCUSSION}

The average workload of a primary-care midwife, measured in hours of actual work, was found to be about 29 hours per week. The average number of on-call-hours decreased from 56 in 2001 to 51 in 2004 as a result of the increase in the number of midwives per practice. In 2004, the average time spent on direct client care was almost 12 hours per client, up from 10 hours in 2001. The proportion of non-client-related work was on average $26 \%$. The conclusion is that, in client-related care, a shift has taken place towards fewer clients per midwife but more time per client.

This study started a year after midwives in the Netherlands actually went on strike to protest against their high workload and low pay. During the course of this study, several factors contributed to the changes in the work of an average primary care midwife. After the protests, and shortly before the start of this study, the standard fee for midwifery care were increased, so that a fulltime working 


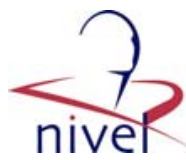

midwife would earn a 'normative' income with the equivalent of 120 births a year, including all preand postnatal care and nonclient- related activities, instead of 150 . This gave midwives the opportunity to increase their income without further increasing their workload. Reducing their workload was initially not an option because of the shortage of midwives. However, in 1994, the capacity of the midwifery schools had already been increased, leading to a higher output of newly qualified midwives since 1998. Between 2000 and 2004, the number of primary-care midwives increased by 18\% (Kenens and Hingstman, 2004). Equally important was that the number of children born in the Netherlands decreased between 2000 and 2004 by 6\%, from 207,000 to 195,000. It was therefore expected that, between 2001 and 2004, the burden on midwifery care would be reduced and that midwives would be able to choose between reducing their actual workload by working fewer hours a week or spending more time with their clients. In line with earlier complaints that the excessive workload decreased the quality of midwifery care, they chose to spend more time with their clients.

Comparing the work and especially the workload of primary-care midwives in the Netherlands to that of midwives elsewhere is difficult, because of the differences in work setting, client population, employment status (self-employed with no fixed number of working hours or with a contract of employment, with or without fixed working hours) and in the organisation of health care as a whole. Workforce data (the number of caregivers in relation to the population) are no indication of workload, and data on actual working hours of midwives are scarce.

Although almost one in six midwifery practices participated in this study each year, and although those practices formed a representative sample, stratified according to level of urbanisation and practice size, it is not possible to guarantee that the sample is representative for workload. Not every practice we approached wanted or could cooperate, often because of their workload. Therefore, it is possible that the average workload is underestimated.

The choice for time registration by self-reporting was made for a number of reasons. First, in earlier research, two methods of time registration have been tested and compared: self reporting and extensive observations. In both cases, one with community nurses (Vorst-Thijssen et al., 1990) and one with midwives (Jabaaij et al., 1994), selfreported data were as accurate as observational data. Second, collecting observational data may disrupt the working routine of the midwifery practice, which could influence results. Moreover, observing a midwife during all aspects of her work can infringe the privacy of clients.

The data-collection periods were chosen carefully in collaboration with respondents. However, this does not guarantee an atypical period in some practices. However, by collecting additional data over a longer period (the previous 6 months), the registration period was shown to be sufficiently representative.

\section{TABLES AND FIGURES}

Table 1 Average working hours per week per midwife, combined over 4 years, and in 2004 and 2001.

\begin{tabular}{lllllll}
\hline & Average & & 2004 & & \multicolumn{2}{c}{2001} \\
\cline { 2 - 7 } & Hours & $\%$ & Hours & $\%$ & Hours & $\%$ \\
\hline Total of which: & 29.3 & 100 & 28.9 & 100 & 29.7 & 100 \\
Direct+indirect client-related & 21.6 & 73.9 & 20.9 & 72.3 & 22.1 & 74.5 \\
Not client-related & 7.7 & 26.1 & 8.0 & 27.7 & 7.6 & 25.5 \\
\hline
\end{tabular}


Table 2 Average time spent on different aspects of direct client care, in minutes, per woman.

\begin{tabular}{lrrr}
\hline & Minutes & Minutes & Minutes \\
\cline { 2 - 4 } & Average & 2004 & 2001 \\
\hline Aspects of care & & & 32.9 \\
Booking visit & 34.6 & 36.3 & 150.7 \\
Prenatal consultation (11) & 164.2 & 170.5 & 17.5 \\
Consultation and ultrasound & 18.6 & 19.9 & 192.7 \\
Birth (including travel time) & 230.8 & 189.5 & 190.8 \\
Postnatal visits (including travel time) & 190.2 & 16.9 & 16.4 \\
(2) 5, 2 6 6) & & 711.6 & 601.0 \\
Consultation 6 weeks after birth & 16.2 & 654.4 & \\
Total & & & \\
\hline
\end{tabular}

*An average of six postnatal visits in 2001 and 2002, and an average of five postnatal visits in 2003 and 2004.

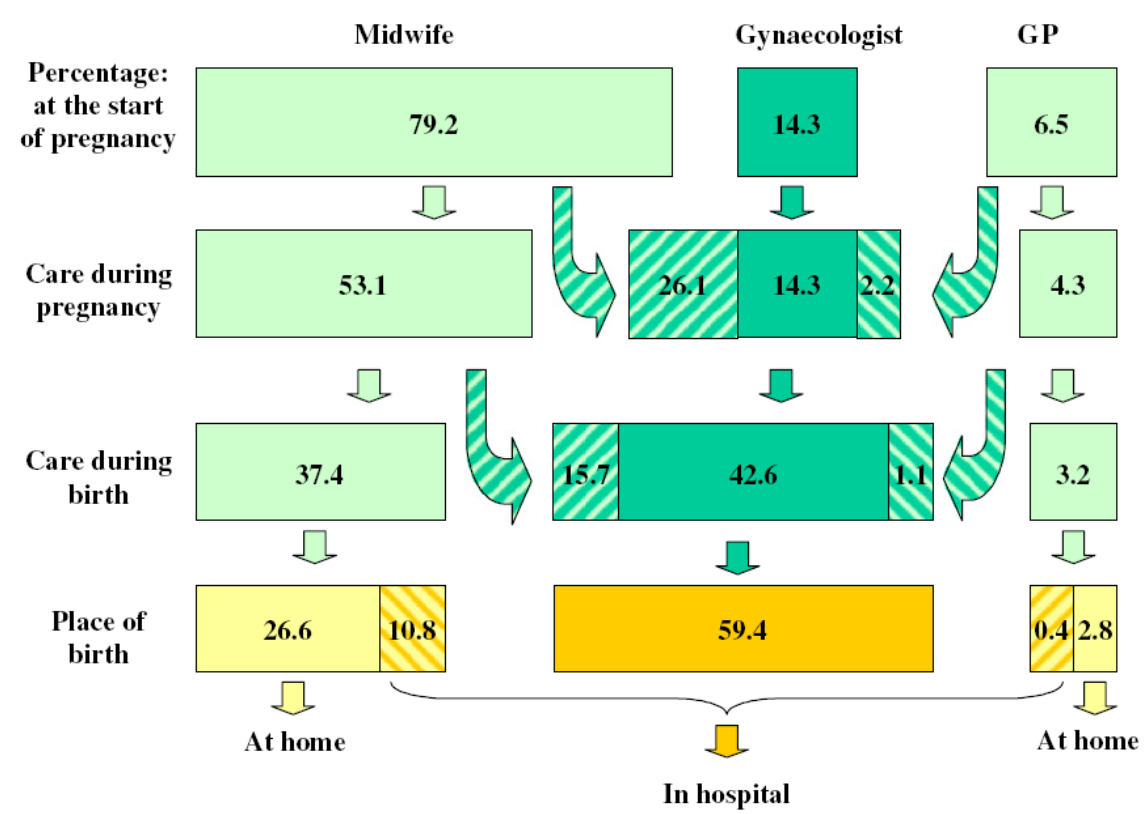

Fig. 1 Maternity care by caregiver and place of birth, 2002.

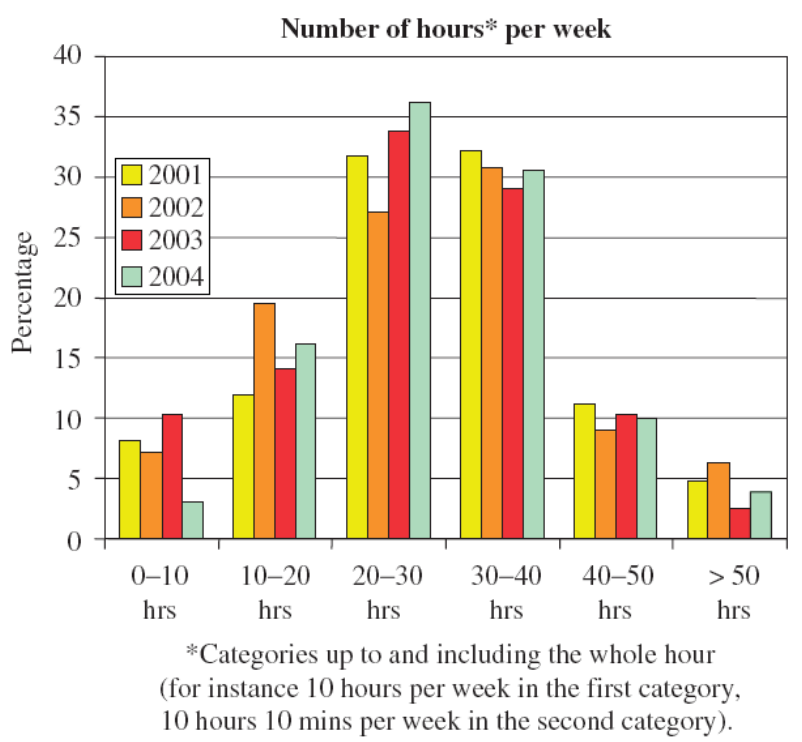

Fig. 2 Range in actual working hours of primary-care midwives. 


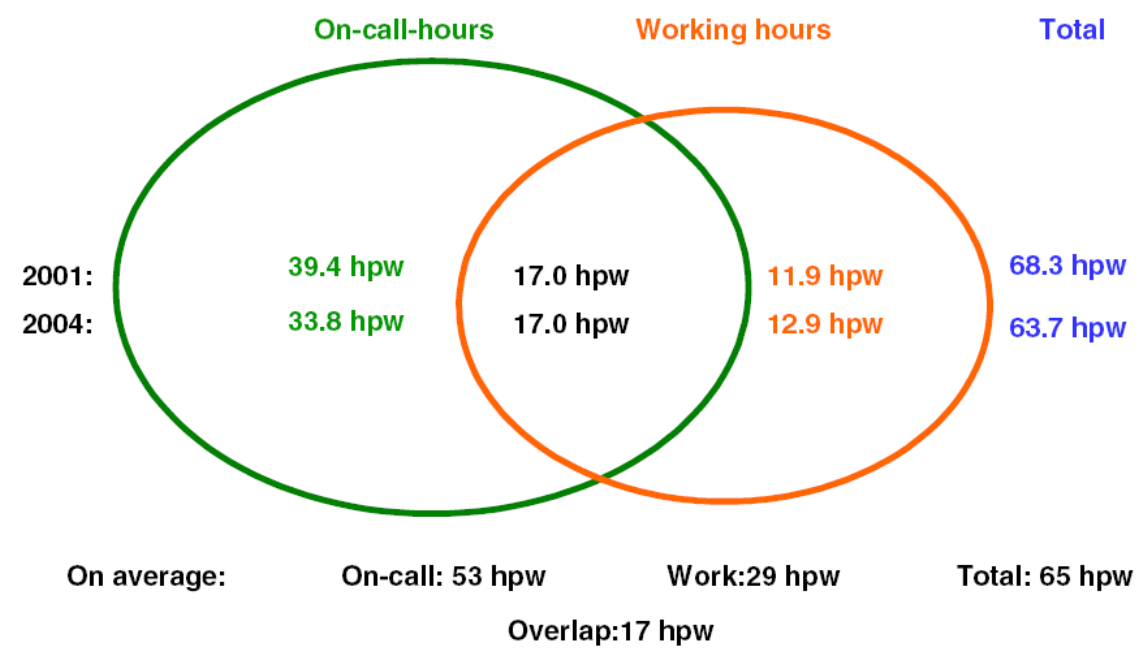

Fig. 3 Overlap between on-call hours and working hours of primary-care midwives (hpw, hours per week).

\section{REFERENCES}

1. Anthony, S., Amelink-Verburg, M.B., Jacobusse, G.W., Pal-de Bruin, K.M., Van der., 2005. Home Birth in the Netherlands 1995-2002. Report concerning the years 2001-2002. Bilthoven/ Leiden, Stichting Perinatale Registratie Nederland/TNO Kwaliteit van Leven.

2. CBS, 1997. Population forecasts 1996-2050. Mndstat bevolk 97/ 1, 62-71.

3. CBS, 2001. Vademecum Health Statistics, The Netherlands 2001. Centraal Bureau voor de Statistiek, Ministerie van Volksgezondheid, Welzijn en Sport, Voorburg, Heerlen.

4. CVZ, 2003. Verloskundig Vademecum, 2003. Eindrapport van de Commissie Verloskunde van het College voor zorgverzekeringen. College voor zorgverzekeringen, Diemen.

5. DeVries, R.G., Benoit, C., Teijlingen, E.R., Van, Wrede, S., 2001. Birth by Design: Pregnancy, Maternity Care and Midwifery in North America and Europe. Routledge, London, New York.

6. DeVries, R., 2004. A Pleasing Birth: Midwives and Maternity Care in the Netherlands. Temple University Press, Philadelphia.

7. Eurostat, 2005. Health Personnel: Absolute Numbers and Rate per 100.000 inhabitants; epp.eurostat.cec.eu.int (last accessed 22 June 2006).

8. Jabaaij, L., Winckers, M., Hingstman, L., Meijer, W., 1994. The Independent Practising Midwife in the Netherlands: Work and Workload. Utrecht, Nivel.

9. Jabaaij, L., Meijer, W., 1996. Home births in the Netherlands: midwifery related factors of influence. Midwifery 12, 129-135.

10. Kenens, R.J., Hingstman, L., 2004. Data From the Registration of Practising Midwives 2004. Utrecht, Nivel.

11. Ministry of Health, Welfare and Sport, 2000. Letter to the Chairman of the Parliamentary Committee on Health, Welfare and Sport d.d. 28 march 2000 about maternity care, Onderwerp: Verloskunde (NDS) 856).

12. NHS Maternity Statistics, England: 2003-2004. Government Statistical Service. Department of Health, London. http:// www.dh.gov.uk/PublicationsAndStatistics/ (last accessed 22 June 2006)

13. Stevens, T., McCourt, C., 2002a. One-to-one midwifery practice part 2: the transition period. British Journal of Midwifery 10, 45-50.

14. Stevens, T., McCourt, C., 2002b. One-to-one midwifery practice part 3: meaning for midwives. British Journal of Midwifery 10, 111-115.

15. Stevens, T., McCourt, C., 2002c. One-to-one midwifery practice part 4: sustaining the model. British Journal of Midwifery 10, 174-179.

16. Vorst-Thijssen, T., Brink-Muinen, A., Van der, Kerkstra, A., 1990. The work of community nurses and community care assistants in the Netherlands. Utrecht, Nivel.

17. Registration data, concerning the number of practising professionals in primary health care; /www.nivel.nl/beroepeninzorg/S (last accessed 26 June 2006). 